\title{
On Design Philosophy of Public Environment Planning in Modern Cities Chuan Sun ${ }^{1, a^{*}}$ and Li Dong ${ }^{2, b^{*}}$ \\ ${ }^{1}$ Hubei University of Education, Wuhan, Hubei 430205, China \\ ${ }^{2}$ Wuhan University of Science and Technology, Wuhan, Hubei 430065, China \\ a25885310@qq.com, bsuper_dongli@sina.com \\ ${ }^{*}$ The corresponding author
}

Keywords: Urban public environment; Planning design; Design philosophy; Display design

\begin{abstract}
This paper studies design philosophy of public environment planning in modern cities. Establishing urban public environment planning system requires unified planning of municipal facilities, road areas, streets and communities, and forbids embezzling public green lands and public facilities. Meanwhile, in urban public environment planning, related departments should focus on serving the public, introducing market mechanism and setting up effective and multiple channels for investment and financing system.
\end{abstract}

\section{Introduction}

The object of design is products. But starting point and ultimate target of design are not products. They aim to meet people's demands, which are the most basic psychological foundation for the development of design. Humans inevitably encounter various problems in survival, hence have various demands. Product designs aim to satisfy different demands of people. Simonov, the psychologist in former Soviet Union pointed out: "Demand is a basis for people to conduct all behaviors and psychological activities, including thinking, emotion and will. Driven by complicated, diverse and varying demands, people directly indicate tendency of self-development. Behaviors are stimulated by demands." Demand is the basis and driving force of human actions and design at the same time. Contemporary psychology research indicates that human actions are driven by motivations, which mainly originate from human demands [1]. Human actions tend to involve certain purposes. They often act in order to attain certain goals.

\section{Display Design of Urban Public Environment Planning}

Display design of urban public environment includes tourist environment design, celebration design, public facility design and public art design, etc. Such designs need to conform to surrounding context, highlight artistic themes and contents of display and deeply impress audience (Fig. 1). Tourist environment design involves design and arrangement of various places historic interests, tourist attractions, botanical gardens and nature reserves. Celebration context design involves decorative design and arrangement for various festive, memorial and ritual activities. Celebration context design create unique environmental atmosphere by beautifying the display space [2].

Conduct careful inspection on exhibition site. Check graph papers and various data on site. Understand display contents, objects, picture quantity and facilities. Based on text scripts, collect related materials on design and technique, prices, budget, relevant policies and regulation, as well as historical and cultural information. Propose feasible methods and ways of displays, in order to formulate schemes and plans. 


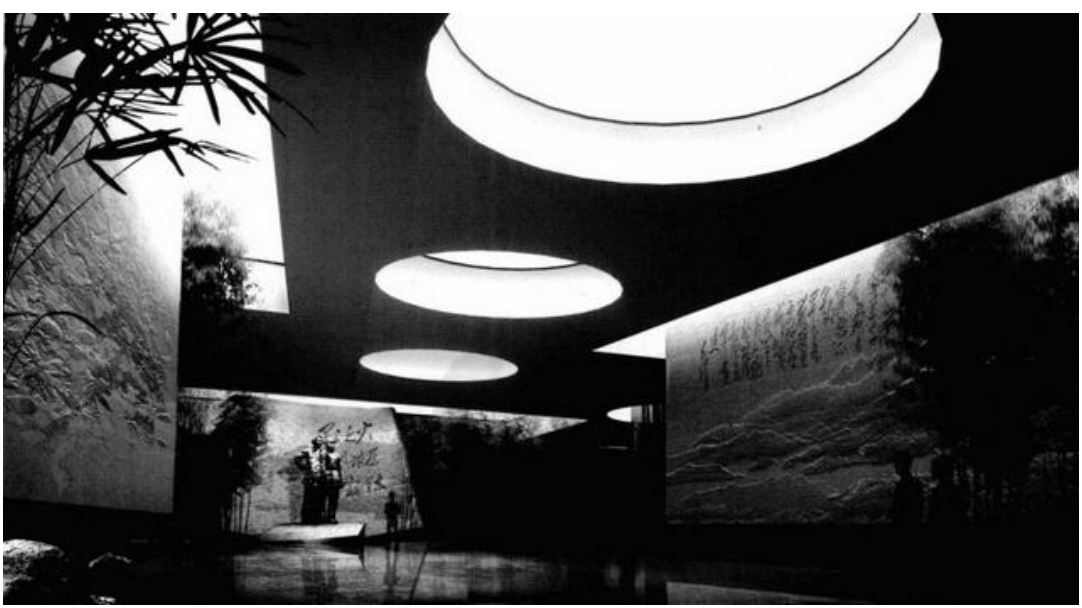

Figure 1. Display design of Jing Gangshan Revolution Museum

\section{Sculptures and Urban Public Environment Planning and Design}

Public space involves the trait of openness. Public art refers to the forms of art creation and context design in the open space. Sculptures are the component part and symbol in this public and open space.

Over thousands of years of human civilization development, ecological balance of nature have been increasingly damaged. Although the industrial revolution created comfortable environment for people, it also caused great harm to ecological environment. Protecting natural ecology has become the shared calling for all people. Nowadays, due to increasing competitiveness and mounting pressure, more and more people also live in busy, fast-paced and stressful urban lifestyles, unable to relax and join in leisure activities. In environment production and construction, integrating nature and humanity is the emphasis of modern public environment planning and construction (Fig.2). In recent few decades, interdependent correlation between natural landscape, topography, ground features and artificial environment has achieved rapid and huge development in Japan. For instance, in Kosaka forest park of Gifu Prefecture, the public entertainment space involves designs of galleries, steps and slides without damaging forests and plants. In order to integrate into natural mountains and trees, as well as nearby views in parks, correlation between sculptures and nature should be considered in design.

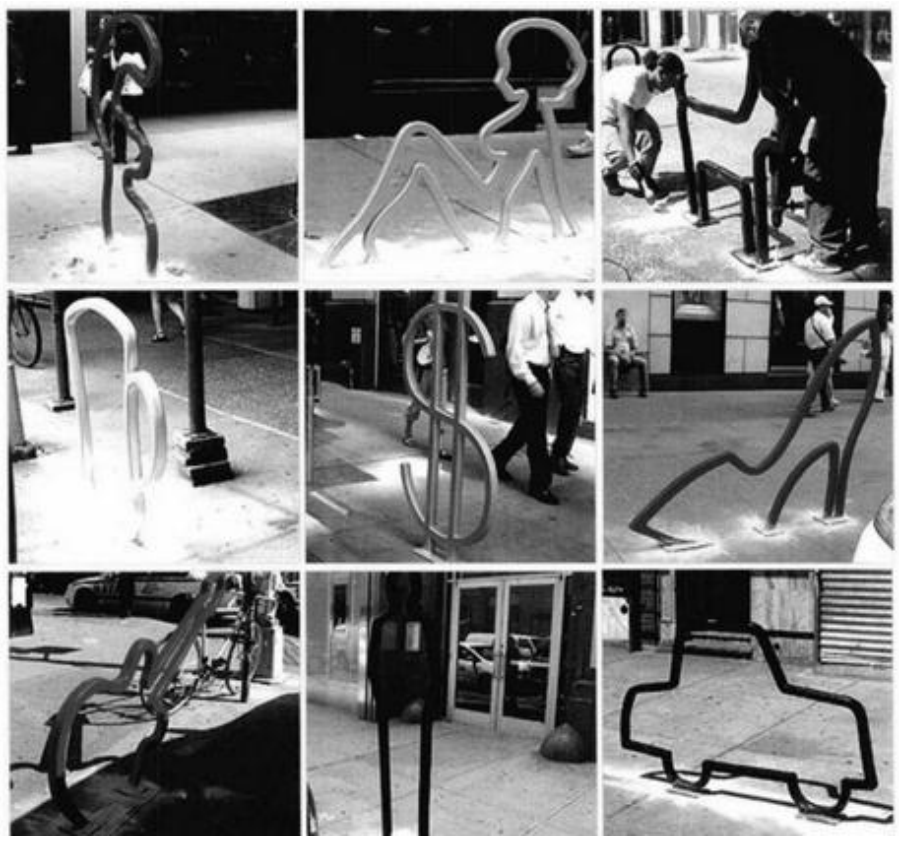

Figure 2. Bionics design cases 


\section{Humanized Design Applied in Urban Public Environment Planning and Design}

Security. Security is the primary condition for human survival. On one hand, in terms of functions, facilities should not only consider ordinary people, but also safety demands of children, old and disabled people (Fig. 3). They should try to meet the demands of different people so as to enhance levels of security. On the other hand, as for models, colors and material use, public facilities should not pose any physical and psychological harm to users [3].

Comfort. Comfort of urban public facilities refers to that residents are able to enjoy relaxed and leisure lifestyles, and avoid harms from chaotic external context (Fig.4). Such comfort involves whether different facilities have functions based on human engineering, and whether satisfy their emotional demands from the angle of environmental psychology. These factors directly concerns functions of urban public facilities, and impacts outdoor life quality of urban residents [4].

Identifiability. Identifiability of urban public facilities also impact application performance (Fig.5). Facilities with obvious identifiability can guide residents to use and operate environmental facilities in correct ways. On the one hand, it enhances the rate of facility utilization. On the other hand, it can also prevent artificial damages caused by incorrect use or operation.

Concordance. Concordance involves three connotations. Firstly, it refers to concordance between component elements of public facilities. Secondly, concordance between public facilities. As they are in the same outdoor context, although facilities may have different functions and users, they should need to indicate concordance and unity in aspects such as appearances, materials and colors,etc. Lastly, it refers to concordance between public facilities and external context. Public facilities are used in outdoor environment [5]. As a result, in addition to safety, comfort and identifiability, good facilities should also integrate artificial traits and natural environment (Fig. 6).

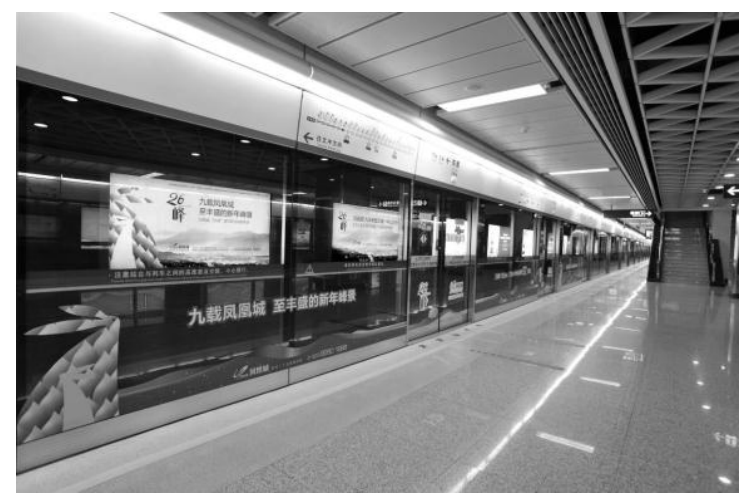

Figure 3. Security

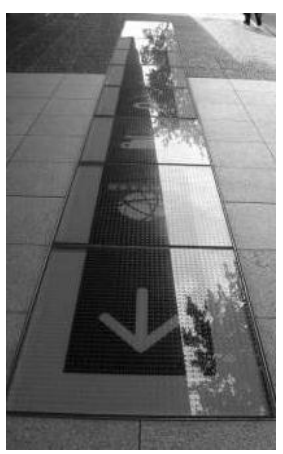

Figure 5. Identifiability

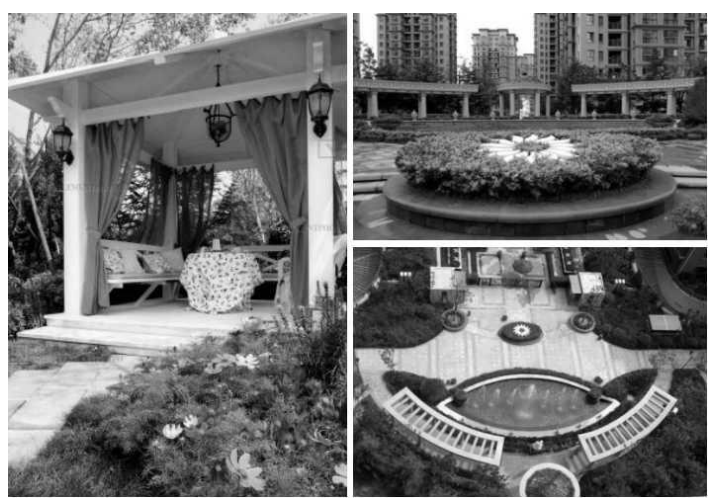

Figure 4. Comfort

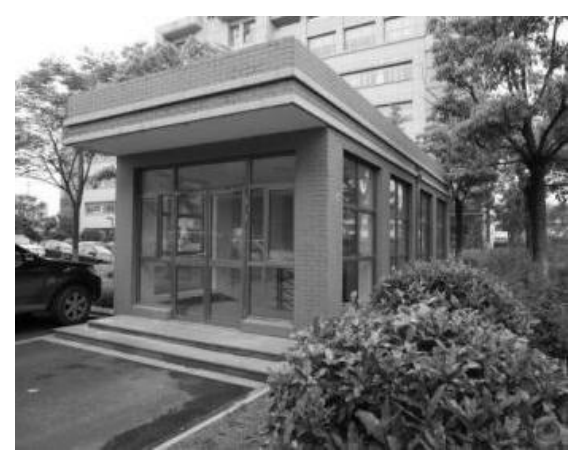

Figure 7. Care

Care. Urban public facilities are outdoor facilities for "people" to use. Their final purpose is to demonstrate understanding and care for outdoor life, concern for people's survival in outdoor, defend and concern for human dignity and value, in order to respect and care for people. As result, they need to focus on external and humanized living conditions, as well as overall development of ideal 
personality. Moreover, public facilities should establish harmonious relationships between humans, community, technology, natural environment, as well as people's mental and physical well-being (Fig. 7). In addition, they also need to advocate aesthetic lifestyles, create safe and comfortable living environment for all urban residents and enhance their tastes and quality in life.

Furthermore, research and studies conducted by experts in biology and epidemic disease indicate that aging and disability are objective traits. For countries and regions without major wars, large-scale violence and natural disasters, the aging of population is an obvious trend. Elderly people show decline in physical conditions, which add new problems and conflicts to urban obstacles and barriers. To help more disabled and handicapped people gain more rights, interests and joys in life requires care and concern of the whole society. It is also the obligation of designers. Barrier-free facilities need to consider the relationship between people and facilities, which emphasizes on safety and comfort. They should enable users to move freely and safely in certain ranges. Barrier-free facilities can not only measure the overall levels of material standards in a nation, but also reveals its spiritual civilization, and concerns national image, urban image and international image as well.

\section{Summary}

With the rapid development of urban construction, some urban administrative departments began to pay attention to related issues in urban public environment, aiming to achieve systematization and scientization of public environment planning and design. Similar to some conceptualized urban elements, such as housing estates, dwelling districts, centers, parks and greenbelt, urban public environment planning will soon be included as entity elements in urban planning and construction in future China.

\section{References}

[1] Xing Gurui, Cai Keguang. Research on Overall Urban Planning Performance Evaluation Framework [J] Urban Problems, (2013) No.06, P223-227. (In Chinese)

[2] Jia Haifeng, Yao Hairong, Tang Ying. Urban Rainfall Runoff Control and Planning Methods and Cases [J]. Hydroscience Development, (2014) No.01, P287-288. (In Chinese)

[3] Hu Xiaowan, Yu Jin. Livable City Planning and Construction Based On the Example of Yan Tian District, Shenzhen [J] Special Zone Economy, (2014) No.02, P393-395. (In Chinese)

[4] Wang Shaobin. Creating Display Form And Spatial Experiences Of Regional And Culture Traits__ Take The Design Practice Of Yunfu Urban Planning Exhibition Museum As The Example[J]. Decoration,(2014)No.01,P186-187. (In Chinese)

[5] Li Posong, Zhutan. Research on The Theory of Energy “Decoupling” In Urban Planning Strategy Environmental Impact Assessment [J] ecological economy, (2014) No.01, P216-219. (In Chinese)

[6] Liu Tianqi. Guide for Regional Environmental Planning Method [M] Chemical Industry Press, (2001). (In Chinese)

[7] Dong Jianhong. China's Urban History [M] China Building Industry Press, (2004). (In Chinese)

[8] Amos Rapoport.Cultural Features and Architectural Design [M] China Building Industry Press, (2004). (In Chinese)

[9] J.C.Moughtin. Beautification and Decoration [M] China Building Industry Press, (2004). (In Chinese)

[10] Fu Chonglan. China City Development Report [M] China Social Science Press, (2014). (In Chinese) 